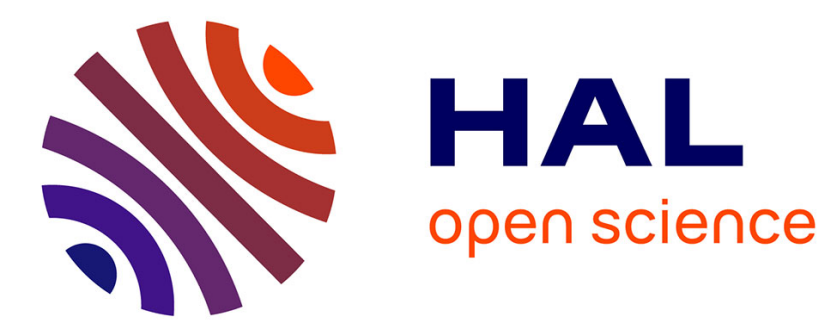

\title{
Oxygen isotopic diversity of chondrule precursors and the nebular origin of chondrules
}

Yves Marrocchi, Johan Villeneuve, Valentina Batanova, Laurette Piani, Emmanuel Jacquet

\section{- To cite this version:}

Yves Marrocchi, Johan Villeneuve, Valentina Batanova, Laurette Piani, Emmanuel Jacquet. Oxygen isotopic diversity of chondrule precursors and the nebular origin of chondrules. Earth and Planetary Science Letters, 2018, 496, pp.132-141. 10.1016/j.epsl.2018.05.042 hal-02357534

\section{HAL Id: hal-02357534 \\ https://hal.univ-lorraine.fr/hal-02357534}

Submitted on 10 Nov 2019

HAL is a multi-disciplinary open access archive for the deposit and dissemination of scientific research documents, whether they are published or not. The documents may come from teaching and research institutions in France or abroad, or from public or private research centers.
L'archive ouverte pluridisciplinaire HAL, est destinée au dépôt et à la diffusion de documents scientifiques de niveau recherche, publiés ou non, émanant des établissements d'enseignement et de recherche français ou étrangers, des laboratoires publics ou privés. 


\title{
1 Oxygen isotopic diversity of chondrule precursors and the
}

\section{2 nebular origin of chondrules}

3

4

5

6

7

8

9

10

11

12

13

14

15

16

17

18

19

20

21

22

23

24

25

26

27

Yves Marrocchi ${ }^{1, *}$, Johan Villeneuve ${ }^{1}$, Valentina Batanova ${ }^{2}$, Laurette Piani ${ }^{1}$ and Emmanuel Jacquet $^{3}$

${ }^{1}$ CRPG, CNRS, Université de Lorraine, UMR 7358, Vandoeuvre-lès-Nancy, 54501, France.

${ }^{2}$ Université Grenoble Alpes, ISTerre, CNRS, UMR 5275, Grenoble, F-38000, France. ${ }^{3}$ IMPMC, CNRS \& Muséum national d'Histoire naturelle, UMR 7590, CP52, 57 rue Cuvier, 75005 Paris, France

Correspondence: *yvesm@crpg.cnrs-nancy.fr

\begin{abstract}
FeO-poor (type I) porphyritic chondrules formed by incomplete melting of solid dust precursors via a yet-elusive mechanism. Two settings are generally considered for their formation: (i) a nebular setting where primordial solids were melted, e.g. by shock waves propagating through the gas and (ii) a collisional planetary setting. Here we report a method combining high-current electron microprobe X-ray mapping and quantitative measurements to determine the chemical characteristics of relict olivine grains inherited from chondrule precursors. We find that these olivine crystals are Ca-Al-Ti-poor relative to host olivine crystals. Their variable $\Delta^{17} \mathrm{O}$, even in individual chondrule, is inconsistent with derivation from planetary interiors as previously argued from $120^{\circ}$ triple junctions also exhibited by the
\end{abstract}


chondrules studied herein. This indicates that chondrule precursors correspond to solid nebular condensates formed under changing physical conditions.

We propose that porphyritic chondrules formed during gas-assisted melting of nebular condensates comprising relict olivine grains with varying $\Delta^{17} \mathrm{O}$ values and Ca-Al-Ti-rich minerals such as those observed within amoeboid olivine aggregates. Incomplete melting of chondrule precursors produced Ca-Al-Ti-rich melts (CAT-melts), allowing subsequent crystallization of Ca-Al-Ti-rich host olivine crystals via epitaxial growth on relict olivine grains. Incoming $\mathrm{MgO}$ and $\mathrm{SiO}$ from the gas phase induced (i) the dilution of CAT-melts, as attested by the positive Al-Ti correlation observed in chondrule olivine crystals, and (ii) buffering of the O-isotope compositions of chondrules, as recorded by the constant $\Delta^{17} \mathrm{O}$ values of host olivine grains. The O-isotopic compositions of host olivine grains are chondrule-specific, suggesting that chondrules formed in an array of environments of the protoplanetary disk with different $\Delta^{17} \mathrm{O}$ values, possibly due to variable solid/gas mixing ratios. (1)

.

6 Keywords: chondrule, oxygen isotopes, relict olivine, epitaxial growth, gas-melt interactions 


\section{1- Introduction}

Chondrules (millimeter-sized igneous spheroids containing silicates, metal, sulfides, and glass) are the major high-temperature components of primitive meteorites (chondrites), suggesting that most inner solar system materials were affected by their formation. However, the underlying mechanism(s) of their formation remains a mystery and diverse scenarios are debated in contemporaneous literature. A key clue to their origin would be the identification of the precursor material that was melted to form chondrules. In this effort, cosmochemists may find help in the incomplete melting of most chondrules, as evidenced by their widespread porphyritic texture (Hewins et al., 2005). Indeed, relict grains inherited from chondrule precursors are identifiable. Forsteritic grains in high-FeO (type II) porphyritic chondrules were presumably inherited from precursors formed in more reducing conditions than their current host (Nagahara, 1981; Scott and Jones, 1990). Conversely, "dusty" grains, i.e., crystals speckled with Fe-rich metal beads, in low-FeO (type I) chondrules are commonly attributed to oxidized precursors that underwent reduction during formation of their host chondrules (Lemelle et al., 2001; Leroux et al., 2003; Nagahara, 1981; Rambaldi, 1981). These examples represent only a fraction of the existing relicts. In type I chondrules - the dominant type in carbonaceous chondrites and hence the main asteroid belt-relict grains from reduced precursors are not so easily recognizable.

Oxygen isotopic systematics may help to identify such relicts (Kimura et al., 2011; Kunihiro et al., 2004, 2005; Rudraswami et al., 2011; Schrader et al., 2013; 2015; Tenner et al., 2013, 2015; Ushikubo et al., 2012). Indeed significant isotopic diversity is observed among solar system materials, from ${ }^{16} \mathrm{O}$-rich refractory inclusions (calcium-aluminum-rich inclusions (CAIs), amoeboid olivine aggregates (AOA)) to ${ }^{16} \mathrm{O}$-poorer chondrules (Clayton, 2003). Type I chondrules exhibit significant variability and define a broad line in the oxygen 
three-isotope diagram that is not specific to chondrules of a given chondrite or to particular chondrite type and known as the primitive chondrule minerals (PCM) line (Ushikubo et al., 2012). The underlying ${ }^{16} \mathrm{O}$ variability could result from (i) physical mixing of grains of different origins within the solid chondrule precursors (Hezel \& Palme, 2007; Tenner et al., 2015) and/or (ii) high-temperature exchanges between the chondrule melt and the surrounding gas (Marrocchi and Chaussidon, 2015). Secondary ion mass spectrometer (SIMS) analyses of olivines within a single chondrule typically reveal homogeneous oxygen isotopic compositions (Chaussidon et al., 2008; Tenner et al., 2015). Yet, in some chondrules, some olivines are ${ }^{16} \mathrm{O}$-enriched compared to their neighbors (Kunihiro et al., 2005; Rudraswami et al., 2011): these are generally considered to be relict grains, even if they are not petrographically manifest (Ushikubo et al., 2012).

Despite these additions to the known inventory of relict grains, their origin remains unclear. Relict olivine grains could correspond to (i) early condensates from the gas of the solar protoplanetary disk (Cohen et al., 2004; Jacquet and Marrocchi, 2017; Russell et al., 2005; Yurimoto and Wasson, 2002), (ii) collisional debris from early-generation planetesimals (Libourel and Chaussidon, 2011; Libourel and Krot, 2007) and/or (iii) earlier generations of chondrules (e.g., Ruzicka et al., 2007). Progress on the identification of the origin of relict olivine grains is frustrated by our poor understanding of their abundance, distribution and specific chemical compositions (Pack et al., 2005; 2004; Ruzicka et al., 2007). Among isotopic studies, only a few in situ measurements of olivine are generally performed within a single chondrule (usually 2-10; Rudraswami et al., 2011), leading to an misestimate of the abundance of relict olivine grains (and relict-bearing chondrules) and a lack of knowledge of their isotopic characteristics. Furthermore, there are no clear majorelement signatures and/or textural features that facilitate the recognition of relict olivine grains (Jones et al., 2004; Ushikubo et al., 2012). Consequently, the message carried by relict 
107 olivine grains remains difficult to decipher, however fundamental it would be to understand 108 the origin of chondrules.

109 Here we report a new method combining high-resolution X-ray maps, electron 110 microprobe analyses, and SIMS oxygen isotope measurements to quantitatively assess for the 111 first time the nature of relict olivine grains in type I chondrules. This method was successfully 112 applied to type I porphyritic chondrules in the CM-related ungrouped chondrite Northwest 113 Africa (NWA) 5958 (Jacquet et al., 2016) and provides new information on the formation conditions of the first solids of the solar system.

\section{2- Material and methods}

NWA 5958 is a carbonaceous chondrite found in the Moroccan desert in 2009 that shares numerous similarities with the $\mathrm{CM}$ chondrite group. This meteorite shows limited terrestrial weathering and a low degree of aqueous alteration (Jacquet et al., 2016). Its bulk oxygen isotopic composition $\left(\Delta^{17} \mathrm{O}=-4.3 \%\right.$ ) is more ${ }^{16} \mathrm{O}$-rich than all $\mathrm{CM}$ chondrites, further supporting a limited alteration episode (Marrocchi et al., 2018; Verdier-Paoletti et al., 2017). As previous $\mathrm{O}$ isotope studies have revealed $\mathrm{CO}$ chondrules to be richest in relicts (Tenner et al., in press), this meteorite, as a member of the CM-CO clan, was a sample of choice to increase their chances of discovery.

We surveyed all type I chondrules in thick section NWA 5958-1 (from the Muséum national d'Histoire naturelle collection, Paris, France) of NWA 5958. The X-ray map of NWA5981-1 was reported elsewhere (Fig. 1 of Jacquet et al., 2016). Chondrules were examined microscopically in reflected light. Scanning electron microscope observations were performed at CRPG using a JEOL JSM-6510 with $3 \mathrm{nA}$ primary beam at $15 \mathrm{kV}$. Among 32

131 Mg-rich porphyritic Type I chondrules examined, we selected 3 olivine-rich chondrules (Fig. 
132 1, 2, S1-S3). High-resolution X-ray element distribution maps were performed at the Institut

133 des Sciences de la Terre (ISTerre, Grenoble, France), using a JEOL JXA-8230 electron

134 microprobe analyzer (EMPA) equipped with five wavelength-dispersive spectrometers (WDS)

135 and one silicon drift detector energy-dispersive spectrometer (EDS; Batanova et al., 2015).

136 Analysis were performed with an acceleration voltage of $20 \mathrm{kV}$, beam current of $500 \mathrm{nA}, 1.5$ -

$137 \mu \mathrm{m}$ step size, and dwell time of $500 \mathrm{~ms}$. Al, Ca, Cr, Mn and Ti were measured by WDS while

$138 \mathrm{Fe}, \mathrm{Si}$ and $\mathrm{Mg}$ were measured by EDS. Each map last 24 hours followed by 8 hours of

139 quantitative analyses. Detection limits were below $40 \mathrm{ppm}$ for $\mathrm{Al}, \mathrm{Ca}, \mathrm{Ti}, \mathrm{Cr}$ and $\mathrm{Mn}$ as

140 estimated from minimum differences between the average concentrations of the visually

141 distinct homogeneous zones and standard deviations of concentration of homogeneous zones.

142 These X-ray maps are semi-quantitative, as the background was not quantified by performing

143 similar off-peak maps. However, quantitative analyses of all olivine grains large enough to be

144 isotopically characterized by SIMS were then performed with the following conditions:

145 accelerating voltage $20 \mathrm{kV}$, probe current $900 \mathrm{nA}$, beam diameter $1 \mu \mathrm{m}$, and $320 \mathrm{~s}$ total

146 peak/background counting time. Such a high current and long counting time allow very low

147 detection limits estimated to be $10 \mathrm{ppm}$ for $\mathrm{Al}, \mathrm{Ca}, \mathrm{Ti}, \mathrm{Cr}$ and $\mathrm{Mn}$. The ZAF software was

148 used for matrix corrections (see Batanova et al. 2015 for further details).

149 We measured the oxygen isotopic compositions of chemically characterized olivine

150 crystals with a CAMECA ims 1270 E7 at CRPG-CNRS (Nancy, France). ${ }^{16} \mathrm{O}^{-},{ }^{17} \mathrm{O}^{-}$, and ${ }^{18} \mathrm{O}^{-}$

151 ions produced by a $\mathrm{Cs}^{+}$primary ion beam $(\sim 15 \mu \mathrm{m}, \sim 4 \mathrm{nA})$ were measured in multi-collection

152 mode with two off-axis Faraday cups (FC) for ${ }^{16,18} \mathrm{O}^{-}$and the axial $\mathrm{FC}$ for ${ }^{17} \mathrm{O}^{-}$. To remove

$153{ }^{16} \mathrm{OH}^{-}$interference on the ${ }^{17} \mathrm{O}^{-}$peak and to maximize flatness atop the ${ }^{16} \mathrm{O}^{-}$and ${ }^{18} \mathrm{O}^{-}$peaks, the 154 entrance and exit slits of the central FC were adjusted to obtain mass resolution power of $155 \sim 7000$ for ${ }^{17} \mathrm{O}^{-}$. The multicollection FCs were set on exit slit $1(\mathrm{MRP}=2500)$. Total 156 measurement times were $240 \mathrm{~s}$ (180s measurement +60 s pre-sputtering). We used three 
157 terrestrial standard materials (San Carlos olivine, magnetite and diopside) to define the

158 instrumental mass fractionation line for the three oxygen isotopes and correct for instrumental 159 mass fractionation for olivine. To obtain good precision on analytical measurements, we 160 analyzed, in order, 4 standards, 8 chondrule olivine crystals and 4 standards. Typical count

161 rates obtained on the San Carlos olivine standards were $2.5 \times 10^{9} \mathrm{cps}$ for ${ }^{16} \mathrm{O}, 1.0 \times 10^{6} \mathrm{cps}$

162 for ${ }^{17} \mathrm{O}$, and $5.4 \times 10^{6} \mathrm{cps}$ for ${ }^{18} \mathrm{O}$. The number of $\mathrm{Mg}$-rich olivines analyzed per chondrule

163 were 45, 45 and 28, with typical uncertainties of $0.2,0.4$ and $0.7 \%$ or for $\delta^{18} \mathrm{O}, \delta^{17} \mathrm{O}$ (measured 164 relative to standard mean ocean water, SMOW, as $\delta^{17,18} \mathrm{O}=$ 165 $\left.\left[\left({ }^{17,18} \mathrm{O} /{ }^{16} \mathrm{O}\right)_{\text {sample }} /\left({ }^{17,18} \mathrm{O} /{ }^{16} \mathrm{O}\right)_{\text {SMOW }}-1\right] \times 1000 \%\right)$, and $\Delta^{17} \mathrm{O} \quad\left(=\delta^{17} \mathrm{O}-0.52 \times \delta^{18} \mathrm{O}\right)$, 166 respectively (Table S1).

\section{3- Results}

All porphyritic chondrule textural types are present in NWA 5958, i.e., porphyritic olivine-rich (PO), porphyritic olivine-pyroxene (POP), and porphyritic pyroxene-rich (PP); Figs. 1-3). Among the chondrules examined, two PO chondrules (Ch-1 and $\mathrm{Ch}-7)$ were chosen for detailed examination. They are characterized by many variably-sized $(\approx 30-300$

$174 \mu \mathrm{m}$ ) subhedral to euhedral olivine grains meeting in $120^{\circ}$ triple junctions (Figs. 1, 2, S1-S2)

175 first described by (Libourel and Krot, 2007), altered mesostases, and Fe-Ni metal beads (Figs. 1, 2A, and S1-S2). Large, euhedral low-Ca pyroxenes surround both chondrules, with

177 resorbed or poikilitically enclosed olivines (Figs. 1, 2, S1-S2, Friend et al., 2016). The third

178 chondrule selected, Ch-2, was a POP chondrule showing radial zoning with an olivine- and 179 (altered) mesostasis-rich interior and an outer zone dominated by low-Ca pyroxenes parallel 180 to the surface (Fig. S3). 
182 (Fig. 2A, S2-S3) but high-resolution titanium X-ray maps reveal important chemical 183 variations in the three chondrules (Fig. 2B, S1-S3). In some cases, these compositional 184 variations occur within single crystals, with Ti-rich olivine engulfing Ti-poor olivine, 185 implying overgrowth on a relict crystal (Fig. 2B). Ti-poor olivine grains are mainly located in 186 the center of chondrule (Fig. 2B) but also occur as the center of olivine crystals dispersed 187 throughout the chondrules (Fig. S2-S3). The overall zoning is comparable to the "inverse 188 zonings" in some cathodoluminescence maps of porphyritic chondrules by (Pack et al., 2004; 189 e.g. their Fig. 2D and 10B) and Kita et al. (2010). Outer-chondrule olivine crystals show 190 oscillatory $\mathrm{Ti}$ zoning over thickness ranging from 10 to $30 \mu \mathrm{m}$ (Fig. 2B, S2-S3), with a 191 tendency to return to lower Ti contents (also seen at the edge of inner-chondrule crystals).

192 This is the first time oscillatory zoning is reported in chondrule olivine (notwithstanding the 193 single-oscillation high-FeO grain of Jacquet and Marrocchi, 2017) for elements other than the 194 slow diffuser phosphorus (McCanta et al., 2016) although such zoning has long been 195 described in pyroxene (e.g, Baecker et al., 2017; Jones, 1996). The overgrowths sometimes 196 exhibit variable thicknesses, with thicker overgrowths toward the exterior of the chondrule 197 (Fig. 2B). High-resolution quantitative analyses of olivine reveal trace element variations 198 within each chondrule, with aluminum and titanium contents varying from 0.02 to 0.2 wt $\%$ 199 and 0.01 to $0.08 \mathrm{wt} \%$, respectively (Table S1). Importantly, both elements are positively 200 correlated in PO chondrules (Fig. 3E and 4E, Tables S1 and S2) whereas the POP chondrule 201 shows no specific correlation (Fig. S4E, Tables S1 and S2). Other well-defined correlations 202 were observed in PO chondrules (Table S1 and S2): (i) $\mathrm{Cr}$ is positively correlated to Fe and $203 \mathrm{Mn}$ and negatively to the $\mathrm{Mg \#}$ (= molar $\mathrm{MgO} /(\mathrm{MgO}+\mathrm{FeO})$ ), (ii) $\mathrm{Fe}$ is positive correlated with 204 Mn. 
A total of 118 SIMS spot analyses were performed in one session and used to assess oxygen isotope systematics of the three mapped and chemically characterized chondrules.

207 Olivine O-isotope compositions plot along the PCM line with $\delta^{17} \mathrm{O}$ and $\delta^{18} \mathrm{O}$ ranging from $208-30.3$ to $+2.75 \%$ and from -27.3 to $+5.1 \%$, respectively (Fig. $3 \mathrm{~A}, 4 \mathrm{~A}$ and S4A, Table S1). 209 All chondrules show internal mass-independent O-isotope heterogeneity beyond analytical 210 uncertainties, with $\Delta^{17} \mathrm{O}$ varying by $>5 \%$ (Fig. 3A, 4A and S4A, Table S1). Most of this 211 variability is carried by Ti, Ca, Al-poor olivine grains whereas (varyingly) Ti, Ca, Al-richer 212 grains cluster around the same $\Delta^{17} \mathrm{O}$ value, producing "orthogonal" relationships (i.e. 213 conjunction of an horizontal and a vertical trends) in $\Delta^{17} \mathrm{O}$ vs. minor element plots (Fig. 3A, 214 4A, and S4). In each chondrule, the horizontal trend which regroups the majority of the grains 215 can be taken as representing the host. That of the two PO chondrules $\left(\Delta^{17} \mathrm{O}=-6.0\right.$ and -6.3 $216 \%$ ) belongs to the ${ }^{16}$ O-rich group of (Ushikubo et al., 2012) whereas the POP chondrule's $217\left(\Delta^{17} \mathrm{O}=-3.0 \%\right)$ fits in the ${ }^{16} \mathrm{O}$-poor one.

\section{4- Discussion}

\section{4-1 Chemical characterization of relict olivines}

Our high-resolution titanium X-ray maps of porphyritic chondrules reveal different populations of olivine grains characterized by variable titanium contents (Fig. 2B, S2-S3). Most Ti-poor olivine grains have oxygen isotopic compositions markedly distinct from their hosts (olivine grains with higher Ti concentrations; Fig. 3B, 4B and S4B, Tables S1 and S2).

227 Following (Ushikubo et al., 2012), we consider olivines with $\Delta^{17} \mathrm{O}$ deviating by $>3 \sigma$ from 228 their host $\Delta^{17} \mathrm{O}$ as relicts (host being the olivine grains showing homogeneous values with 
230 They may be ${ }^{16} \mathrm{O}$-richer $(\mathrm{Ch}-2$ and $\mathrm{Ch}-7)$ or ${ }^{16} \mathrm{O}$-poorer $(\mathrm{Ch}-1)$ than their host olivine. Our 231 results thus demonstrate that olivine $\mathrm{Ti}$ concentrations can constitute a chemical marker of 232 relicts, in addition to isotopic data. Relict olivine grains are also systematically Al-poor (Fig. 233 3C, 4C and S4C, table S1) and, in one chondrule (Ch2), Ca-poor (Fig. 4D) relative to host 234 olivines. However, relict olivine grains are not systemically depleted in Ca relative to the host 235 (Table S1).

Ambiguity remains though regarding those Ti-poor olivine crystals with $\Delta^{17} \mathrm{O}$ similar to the range defined by the host grains (Fig. 3, 4, S4, Table S1). Such grains could correspond to (i) relict grains with O-isotopic compositions coincidentally similar to host crystals or (ii) host olivine with lower Ti content relative to other host grains. Obvious relict olivine grains (i.e. with $\Delta^{17} \mathrm{O}$ outside $3 \sigma$ of the host), are mainly located in the center of chondrules

241 (Fig. 5), whereas the aforementioned ambiguous grains occur at the outer edge of chondrules 242 (Fig. 2, 5, S2-S3), suggesting an host origin (see also next subsection).

Our finding that relict chondrule olivine are $\mathrm{Ca}$, Al, Ti-poor contrasts with the 244 previous notion that refractory-enriched olivines were the relict grains (Pack et al., 2004; 245 Pack and Palme, 2003) but even those workers had reported "inverse zonings" similar to 246 those of this study when dealing with bona fide porphyritic chondrules (Pack et al., 2004). 247 Since refractory forsterite crystals do occur independently in chondrites (Jacquet and 248 Marrocchi, 2017; Pack et al., 2004), the possibility remains that some contributed to 249 chondrule precursors although they were not found in this study. At any rate, this study demonstrates that high-current EMPA mapping (at $500 \mathrm{nA}$ ) and 251 quantitative analyses (at $900 \mathrm{nA}$ ) constitute a powerful method for characterizing relict 252 olivine crystals as it allows very low detection limits for trace elements in olivine $(\approx 10 \mathrm{ppm}$ 253 for $\mathrm{Al}, \mathrm{Ca}, \mathrm{Mn} \& \mathrm{Ti}$; Sobolev et al., 2016) to be reached with limited interaction and emission 254 volumes of $X$-rays in olivine grains (i.e., $\leq 6 \mu \mathrm{m}^{3}$; Batanova et al., 2015). 
Coarse-grained olivine aggregates showing $120^{\circ}$ triple junctions, such as in our PO chondrules analyzed, were interpreted by (Libourel and Krot, 2007) as potential fragments of differentiated planetesimals that experienced disruption early in the Solar System history. In such a scenario, all Mg-rich olivine grains would represent relict minerals that survived the chondrule-forming event(s). However, experimental samples with olivine triple junctions were produced during thermal annealing under nebular conditions, challenging the planetary origin of granoblastic olivine aggregates (GOA; Whattam and Hewins, 2009; Whattam et al., 2008). Our results show that large mass-independent O-isotope variations occur within chondrules showing triple junctions (Fig. 1). This does not support a planetary origin of GOA as crystallization from a magma ocean would result in very limited and mass-dependent $\mathrm{O}$ isotopic fractionation (Richet et al., 1977). For instance, oxygen isotope compositions of primitive basaltic rocks vary within narrow ranges with mass-dependent fractionation limited to less than $1 \%$ (Eiler, 2001). Consequently, it appears that $120^{\circ}$ triple junctions of olivines are not the result of lithostatic pressure (Whattam et al., 2008; Whattam and Hewins, 2009) ours even seem to be shaped by overgrowths rather than the relicts themselves - arguing against a planetary origin of chondrules (Jacquet et al., 2012; Jacquet and Marrocchi, 2017). While derivation of neighboring relicts from independent planetary bodies remains unlikely

274 but conceivable, known (macroscopic) achondrites sample a much more restricted range of $\mathrm{O}$ 275 isotopic compositions (Greenwood et al., 2016).

The relict olivine grains in NWA 5958 are too poor in refractory elements to correspond to phenocrysts in refractory condensed melts as envisioned by (Pack et al., 2004).

278 Their chemical features (Ca-Al-Ti-poor; Fig. 3, 4 \& S4, Table S1) are however similar to 279 olivine in amoeboid olivine aggregates (AOAs; Ruzicka et al., 2012; Sugiura et al., 2009; 
280 Weisberg et al., 2004), which result from condensation from the nebular gas (Krot et al., 281 2004): for example AOA olivines in the same meteorite analyzed by Jacquet and Marrocchi 282 (2017) have concentrations ranging 0.01-0.03 wt $\% \mathrm{TiO}_{2}, 0.03-0.08 \mathrm{wt} \% \mathrm{Al}_{2} \mathrm{O}_{3}$, comparable with our relicts (see section 4.1). Furthermore, olivines within individual AOAs commonly 284 show variable $\Delta^{17} \mathrm{O}$ values that could result from condensation under changing physical conditions (Krot et al., 2004). This support a kinship between AOAs and chondrule precursors, similar to that inferred for part of the precursors of agglomeratic chondrules in CR chondrites (Schrader et al., 2018). The presence of refractory inclusions among chondrule precursors is supported in the literature by the observation of (rare) relict CAIs and AOAs in chondrules (Aléon \& Bourot-Denise, 2008; Krot et al. 2009; Yurimoto and Wasson 2002), aluminumrich chondrules (Russell et al. 2000; Krot and Keil 2002) and volatility-fractionated rare earth element patterns in bulk chondrules (Misawa and Nakamura 1988; Jacquet and Marrocchi 2017 and references therein). However, chondrule precursors are unlikely to be solely AOAs as the latter are ${ }^{16} \mathrm{O}$-rich $\left(\Delta^{17} \mathrm{O}=-15\right.$ to $-22 \%$; Krot et al., 2004) whereas relict olivine grains in NWA 5958 chondrules are isotopically diverse with $\Delta^{17} \mathrm{O}$ ranging from -16.1 to $+0.5 \%$ o (Fig. 6, Table S1). Additionally, relict olivines in $\mathrm{Ch}-1$ are enriched in ${ }^{17,18} \mathrm{O}$ relative to the host grains (Fig. 3, Table S1) and literature data indeed show relict olivine grains either 297 enriched or depleted in ${ }^{16} \mathrm{O}$ relative to the host (Jones et al., 2004; Kita et al., 2010; 298 Rudraswami et al., 2011; Tenner et al., 2015; 2013; Ushikubo et al., 2012). Since the oxygen isotopic characteristics of precursors should be better preserved than minor elements because 300 of slower diffusion of oxygen: e.g., Ryerson et al., 1989), these cannot have been solely 301 AOAs but were plausibly nebular condensates mineralogically analogous to them but 302 characterized by a significant oxygen isotopic diversity. It is interesting to note that the 303 analyzed relict olivines (Table 1) define a $\delta^{17} \mathrm{O}-\delta^{18} \mathrm{O}$ correlation (Fig. 6), described by $\delta^{17} \mathrm{O}=$ $304(1.04 \pm 0.06) \times \delta^{18} \mathrm{O}-(2.78 \pm 0.60)$ that is indistinguishable within errors from the PCM line 
defined by SIMS measurements in chondrules (i.e., amalgamated host and relict data) from

306 different carbonaceous chondrites (Ushikubo et al., 2012). The PCM line may thus have been 307 already established in the chondrule precursors rather than being a result of chondrule 308 formation, although some of the relicts (presumably among those in the range of host 309 compositions) may be recycled chondrule debris.

We note that relict olivine grains are systematically studded with Fe-Ni metal beads (Fig. 2B). Such mineralogical associations could either result from (i) co-condensation of olivine and Fe-Ni metal beads, as observed in some AOAs (Krot et al., 2004) or (ii) subsolidus reduction of $\mathrm{FeO}$ in olivine grains (Lemelle et al., 2001; Leroux et al., 2003). The

314 latter produces peculiar textures with micron-sized Ni-poor (i.e., < 2 wt \%) metal beads 315 surrounded by silica-rich glass layers (Leroux et al., 2003) and defining lines in olivine 316 crystals (Rambaldi, 1981), which are not observed in NWA 5958 chondrules (Fig. 2 and S2). If, on the contrary, the mineralogical association is pristine, the relicts must have condensed at a total pressure $>10 \mathrm{~Pa}$ (i.e., 0.1 mbar) to produce $\mathrm{Fe}-\mathrm{Ni}$ metal beads before condensation of Mg-rich olivine (Ebel, 2006; Ebel and Grossman, 2000; Petaev et al., 2005).

\section{4-3 Chondrule melting and epitaxial growth of host olivine}

The systematic Al-Ti-enrichments (and in some case in Ca, Fig. 4D) of host olivine grains compared to relicts suggest their formation from $\mathrm{Ca}-\mathrm{Al}$-Ti-melts (hereafter CATmelts). Because the surviving relicts are (Ca)-Al-Ti-poor olivine, the melts generated upon heating should have been enriched in those elements compared to the bulk (more or less chondritic) precursor. Specifically, such melts could result from melting of CAI-like nodules and ribbons like those observed within AOAs, which are mainly composed of spinel, Ti-Ca- 
330 Except spinel, all those phases have lower melting temperatures than $\mathrm{Mg}$-rich olivine and 331 their fusion during the high-temperature chondrule-forming event(s) would generate CAT332 melts while preserving ${ }^{16} \mathrm{O}$-rich spinel relicts as occasionally observed in type I chondrules 333 (Rudraswami et al., 2011; Tenner et al., 2015; 2013; Ushikubo et al., 2012). According to 334 equilibrium Ca-partitioning between forsterite and melt (Libourel, 1999) and the large range 335 of $\mathrm{CaO}$ concentrations observed in $\mathrm{PO}$ chondrule mesostasis (i.e., 5-22 wt\%, Jones and Scott, 336 1989; Libourel et al., 2006; Marrocchi and Libourel, 2013), the host olivine grains could 337 present (i) similar Ca concentration than relict grains (e.g., Ch-1 and Ch-2, Table S1) or 338 (ii) Ca-enrichment comparing to relicts (e.g., Ch-7; Fig. 4D, Table S1). In addition, sodium339 enrichments in the CAT-melts would increase the degree of polymerization of the melt and 340 the activity of $\mathrm{CaO}$, thereby promoting the crystallization of Ca-rich host olivine (Libourel et 341 al., 1999, Piani et al., 2016). The presence of CAT-melt would then allow the crystallization of olivine overgrowths 343 around the olivine relicts, by-passing the thermodynamic barrier of nucleation (Fokin et al., 344 2006). Such a process is attested by the textures of olivine grains inferred from Ti X-ray maps 345 that reveal host-olivine crystallization on relict olivine grains via epitaxial growth (Fig. 2B). 346 Such olivine subtraction from the melt would have further enriched the melt in incompatible 347 elements, contributing to the Ca-Al-Ti-rich character of the overgrowths. Interestingly, Ca348 Al-Ti-rich melt inclusions could be observed along the boundary between relict and host 349 olivine grains (Fig. S1). Similar textures have been observed in terrestrial olivine phenocrysts 350 that present olivine overgrowths on relict olivine cores (Sakyi et al., 2012), thus supporting 351 the crystallization of chondrule host olivine grains via epitaxial growth on relict olivine grains 352 inherited from chondrule precursors.

353 Because relicts are still visible in the X-ray maps, diffusion was not efficient enough 354 to homogenize the olivine grains in $\mathrm{Al}$ and $\mathrm{Ti}$. This runs counter to the batch crystallization 
inferred by (Jacquet et al., 2015) and (Jacquet and Marrocchi, 2017) for type I chondrules, at

356 least for this type of texture, in contradistinction to the largely homogeneous isolated

357 refractory forsterites. For diffusion coefficients of order $10^{-14} \mathrm{~m}^{2} / \mathrm{s}$ in the temperature interval

358 of olivine crystallization, the duration of this high-temperature episode must have been

359 limited to no more than a few hours, though possibly not much shorter than this as e.g. Ca

360 zonings appear significantly smoother and thus diffusion-affected.

4-4 Open system behavior

The enhanced thickness of host-olivine overgrowths near the periphery of the chondrules (Fig. 2B) indicates that olivine "nutrients" were sourced from outside, i.e. open system behavior. Indeed, the low $\mathrm{Mg}$ content of $\mathrm{PO}$ chondrule mesostases $(<5 \mathrm{wt} \% \mathrm{MgO}$; Libourel et al., 2006; Marrocchi and Libourel, 2013) suggest that olivine may have become unstable in the CAT-melt and partially dissolved (Soulié et al., 2016) — it is also possible that the rounded to subhedral shapes of the relict olivines observed in NWA 5958 (Fig. 2B) reflect early such partial dissolutions (rather than only diffusive exchange with overgrowths). Under 371 those conditions, further olivine crystallization may have required an influx of $\mathrm{SiO}$ and $\mathrm{MgO}$ 372 from the gas phase. Such an influx has been invoked to account for the pyroxene-rich 373 peripheries of porphyritic chondrules (Libourel et al., 2006; Piani et al., 2016; Marrocchi et al., 374 2016; Tissandier et al., 2002, Hezel et al., 2003, 2006; Krot et al. 2004; Friend et al. 2016) 375 and thus may have similarly occurred during an earlier stage of chondrule crystallization. This 376 is supported by the decreasing $\mathrm{Ca}, \mathrm{Al}$, and $\mathrm{Ti}$ contents of host olivine grains from the center 377 toward the edge of chondrules (Fig. 2B) that likely results from the dilution of CAT-melts by 378 gas-melt interactions (see Jacquet and Marrocchi, 2017). Our emerging scenario thus bears 379 some similarity with the "Open System Fractional Crystallization" model of (Pack et al., 
2004), despite their different assumed (refractory) starting conditions. In such a scheme, the

381 positive relationships between $\mathrm{Al}$ and $\mathrm{Ti}$ contents in olivine grains (Figs. 3E and 4E) simply

382 reflect their common incompatibility in olivine, and their varied abundances (by at least a

383 factor of 10; Table S1) would result from (i) the dilution of CAT-melts by incoming SiO and

$384 \mathrm{MgO}$ from the gas phase and (ii) progressive crystallization of olivine, concentrating $\mathrm{Al}$ and

385 Ti in the melt. The competition between these two processes may have produced the 386 oscillatory character of some of the zoning.

While the Ca-Al-Ti contents of host olivine grains varied during chondrule formation,

388 their O-isotope composition (i.e. $\Delta^{17} \mathrm{O}$; Fig. 3B, 4B and S3B) remained constant. As the host-

389 olivine $\mathrm{O}$ isotope composition nowhere approaches the mean of the observed relicts among

390 the chondrules studied, rather than corresponding to the bulk precursor, must result from

391 exchange with the gas. The O-isotopic composition of the gas must have been different for

392 each chondrule, as host olivine grains in NWA 5958 show different average values $\left(\Delta^{17} \mathrm{O} \approx-\right.$

3936 and $-3 \%$; Figs. 3B, 4B, and S3B; Jacquet and Marrocchi, 2017). These estimates are in

394 agreement with those reported for different types of carbonaceous chondrites (Libourel and

395 Chaussidon, 2011; Rudraswami et al., 2011; Tenner et al., 2015; 2013; Ushikubo et al., 2012),

396 implying that within a single chondrite, chondrules formed in different environments of the

397 protoplanetary disk with varying $\Delta^{17} \mathrm{O}$ values (Tenner et al., 2015; 2013; Ushikubo et al.,

398 2012). As chondrules in individual chondrites largely formed within a clan-specific reservoir

399 (Jones, 2012), such variations occurred on limited spatial and/or temporal scales, e.g., owing

400 to variable solid/gas mixing ratios.

401

402

403

404 


\section{5-Concluding remarks}

406

407

408

409

410

411

412

413

We developed a method combining high-current electron microprobe X-ray mapping (at $500 \mathrm{nA}$ ) and quantitative measurements (at $900 \mathrm{nA}$ ) to determine the chemical characteristics of relict olivine grains in chondrules. They are Ca-Al-Ti-poor compared to their host olivine crystals and are mainly located in the center of chondrules. Ti-poor relict olivines show variable $\Delta^{17} \mathrm{O}$ values in each chondrule, suggesting that chondrule precursors correspond to nebular condensates that formed under changing physical conditions but at pressures above 0.1 mbar. This holds in particular for GOAs with $120^{\circ}$ triple junctions whose mass-independent $\mathrm{O}$-isotope variations preclude a planetary origin.

The important chemical and O-isotope variations observed within each chondrule suggest that chondrules formed via melting of nebular precursors comprising olivine grains with varying $\Delta^{17} \mathrm{O}$ values and CAI-like nodules and ribbons as those observed within AOAs. The resulting CAT-melts allowed subsequent epitaxial growth of Ca-Al-Ti-rich host-olivines on relict olivine grains. Incoming $\mathrm{MgO}$ and $\mathrm{SiO}$ from the gas phase induced (i) dilution of the CAT-melts, as attested by the positive Al-Ti correlation observed in chondrule olivine crystals, and (ii) buffering of the O-isotope compositions of chondrules, as attested by the constant $\Delta^{17} \mathrm{O}$ values of host olivines. The O-isotopic variations between host olivine grains of different chondrules within a single chondrite demonstrate that the chondrules formed in different environments of the protoplanetary disk with different $\Delta^{17} \mathrm{O}$ values, possibly due to variable solid/gas mixing ratios. (1) 
431

432 All the data used in the present article are available by contacting Yves Marrocchi. Laurent 433 Tissandier, Andrey Gurenko and Mathieu Roskosz are thanked for helpful scientific 434 discussions. Nordine Bouden is thanked for his assistance with isotopic measurements. We 435 thanked Dominik Hezel and Ryoji Tanaka for constructive comments and Associate Editor 436 Frederic Moynier for careful editing. This is CRPG-CNRS contribution \#2564. 
456 Fig. 1: Reflected-light optical images of chondrules (A) Ch-1 and (B) Ch-7 from CM-related 457 chondrite NWA 5958. Schematic representations of olivine grains in chondrules (C) Ch-1 and 458 (D) Ch-7 show the numerous $120^{\circ}$ triple junctions (some indicated by red arrows) between 459 Mg-rich olivine crystals.

461 Fig. 2: (A) Back-scattered electron image of PO chondrule Ch-1 in NWA 5958. Ol = olivine, 462 lpx $=$ low-Ca pyroxene, $\mathrm{Fe}-\mathrm{Ni}=\mathrm{Fe}-\mathrm{Ni}$ metal beads and $\mathrm{m}=$ altered mesostasis. $(\mathrm{B}) \mathrm{X}$-ray 463 map of the $\mathrm{Ti}$ distribution in $\mathrm{Ch}-1$, revealing internal structures. Most olivine grains are 464 composed of a Ti-poor core and an epitaxially grown Ti-rich olivine margin. Most Ti-poor 465 olivine is located near the center of the chondrule, whereas outer olivine grains are enriched in 466 Ti. Oscillatory Ti zoning and a decrease in Ti content are observed in peripheral olivine grains 467 (see text).

Fig. 3: (A) Oxygen isotopic composition of olivine crystals in PO chondrule Ch-1 from 470 chondrite NWA 5958, highlighting important mass-independent variations. The terrestrial 471 fractionation line (TFL) and primary chondrule mineral line (PCM) are also drawn. 472 Incompatible element concentrations plotted against $\Delta^{17} \mathrm{O}$ reveal that relict olivine grains are 473 systematically depleted in (B) $\mathrm{TiO}_{2}$ and (C) $\mathrm{Al}_{2} \mathrm{O}_{3}$ relative to their host olivine crystals, which 474 are characterized by variable concentrations of these elements. (D) Mg\# vs. $\Delta^{17} \mathrm{O}$, showing 475 that relict olivine grains have lower iron contents than their host olivines. (E) The positive 476 relationship between $\mathrm{Al}_{2} \mathrm{O}_{3}$ and $\mathrm{TiO}_{2}$ in olivine grains (both oxide concentrations vary by at 477 least a factor of 5) suggests a dilution effect due to incoming $\mathrm{MgO}$ and $\mathrm{SiO}$ from the gas 478 phase (see section 4-2). (F) $\mathrm{CaO}$ vs. $\mathrm{FeO}$ concentrations in olivine grains. 
480 Fig. 4: (A) Oxygen isotopic composition of olivine crystals in PO chondrule Ch-7 from 481 chondrite NWA 5958. The terrestrial fractionation line (TFL) and primary chondrule minerals 482 line (PCM) are drawn. $\Delta^{17} \mathrm{O}$ vs. (B) $\mathrm{TiO}_{2}$, (C) $\mathrm{Al}_{2} \mathrm{O}_{3}$, and (D) $\mathrm{CaO}$ in olivine are displayed. 483 (E) $\mathrm{Al}_{2} \mathrm{O}_{3}$ vs. $\mathrm{TiO}_{2}$ in olivine grains. (F) $\mathrm{CaO}$ vs. $\mathrm{FeO}$ in olivine crystals.

484

485 Fig. 5: (A) X-ray map of the Ti distribution showing the locations of ion probe measurements 486 (colored circles). The color code indicates the deviation from the average $\Delta^{17} \mathrm{O}$ value of the 487 host olivine grains of this chondrule: $\langle 3 \sigma=$ blue, $3-6 \sigma=$ green, $6-9 \sigma=$ yellow, and $>9 \sigma=$ 488 red.

490 Fig. 6: Oxygen three-isotope plot showing the isotopic compositions of relict olivines from 491 NWA 5958. The data define a linear trend that is indistinguishable, within errors, from the 492 PCM line $\left(\delta^{17} \mathrm{O}=[0.997 \pm 0.013] \times \delta^{18} \mathrm{O}-[2.70 \pm 0.11]\right.$; (Ushikubo et al., 2012)).

493

494

495

496

497

498

499

500

501

502

503

504 

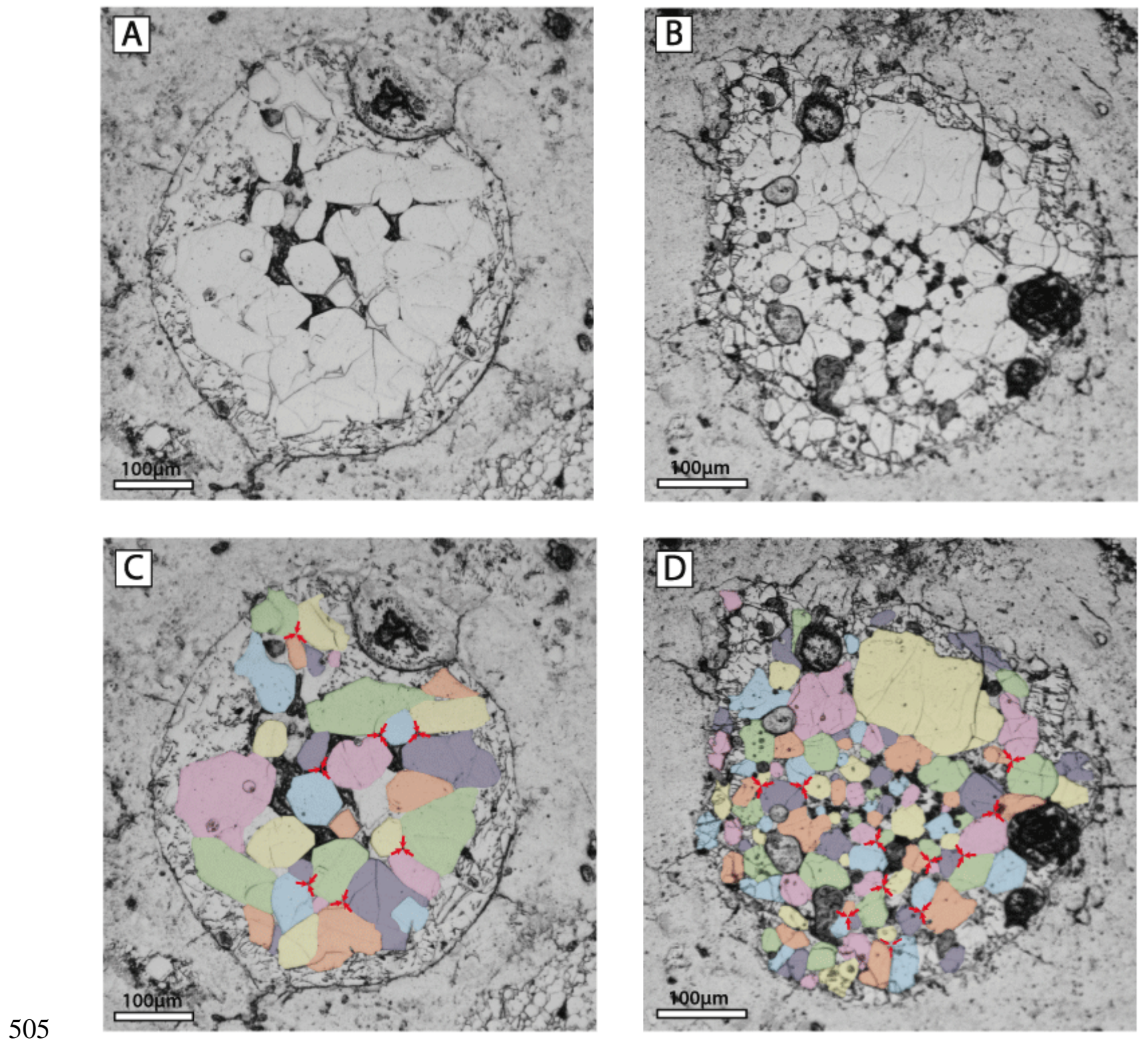

507

508

509 

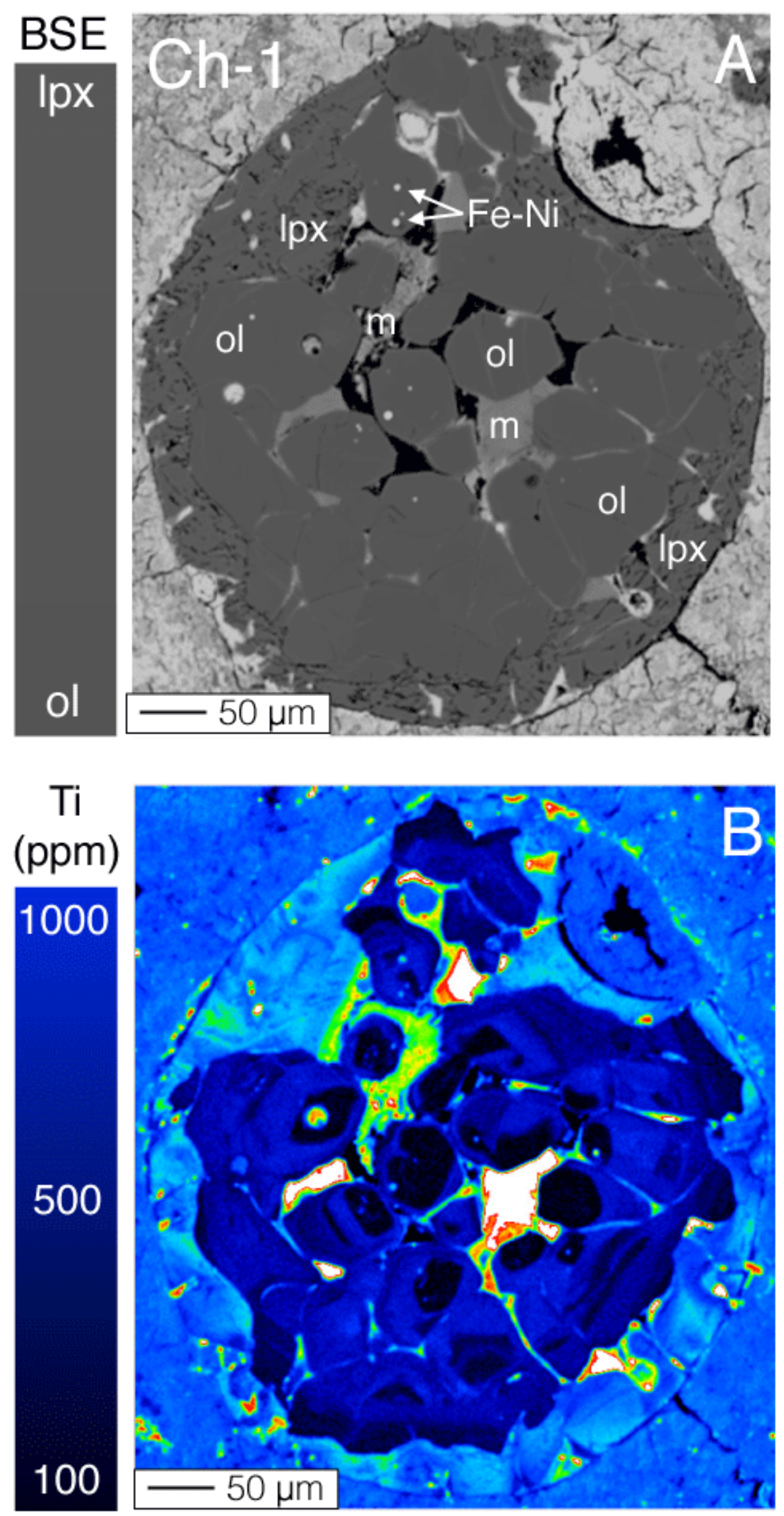

Fig. 2 

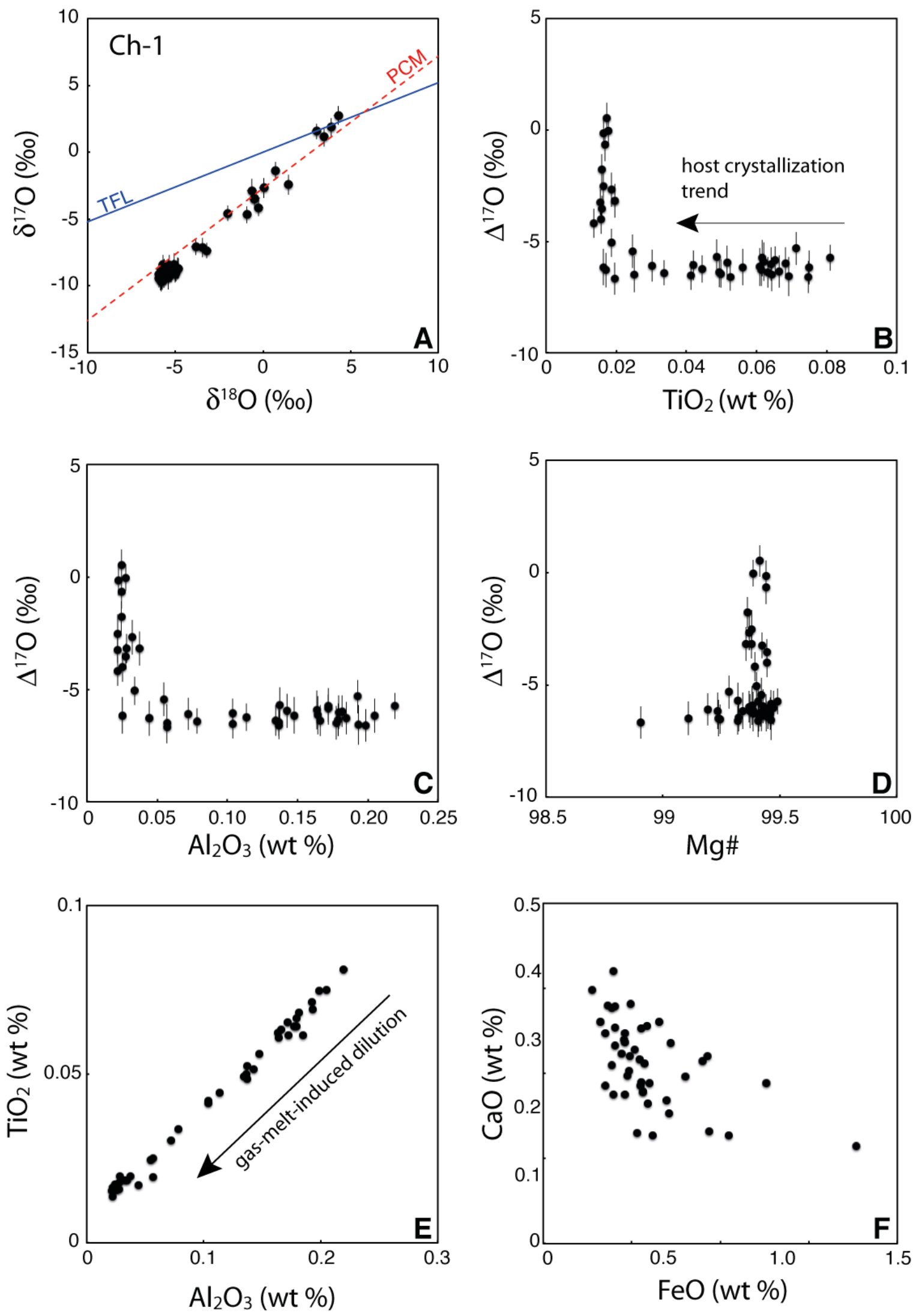

Fig. 3 

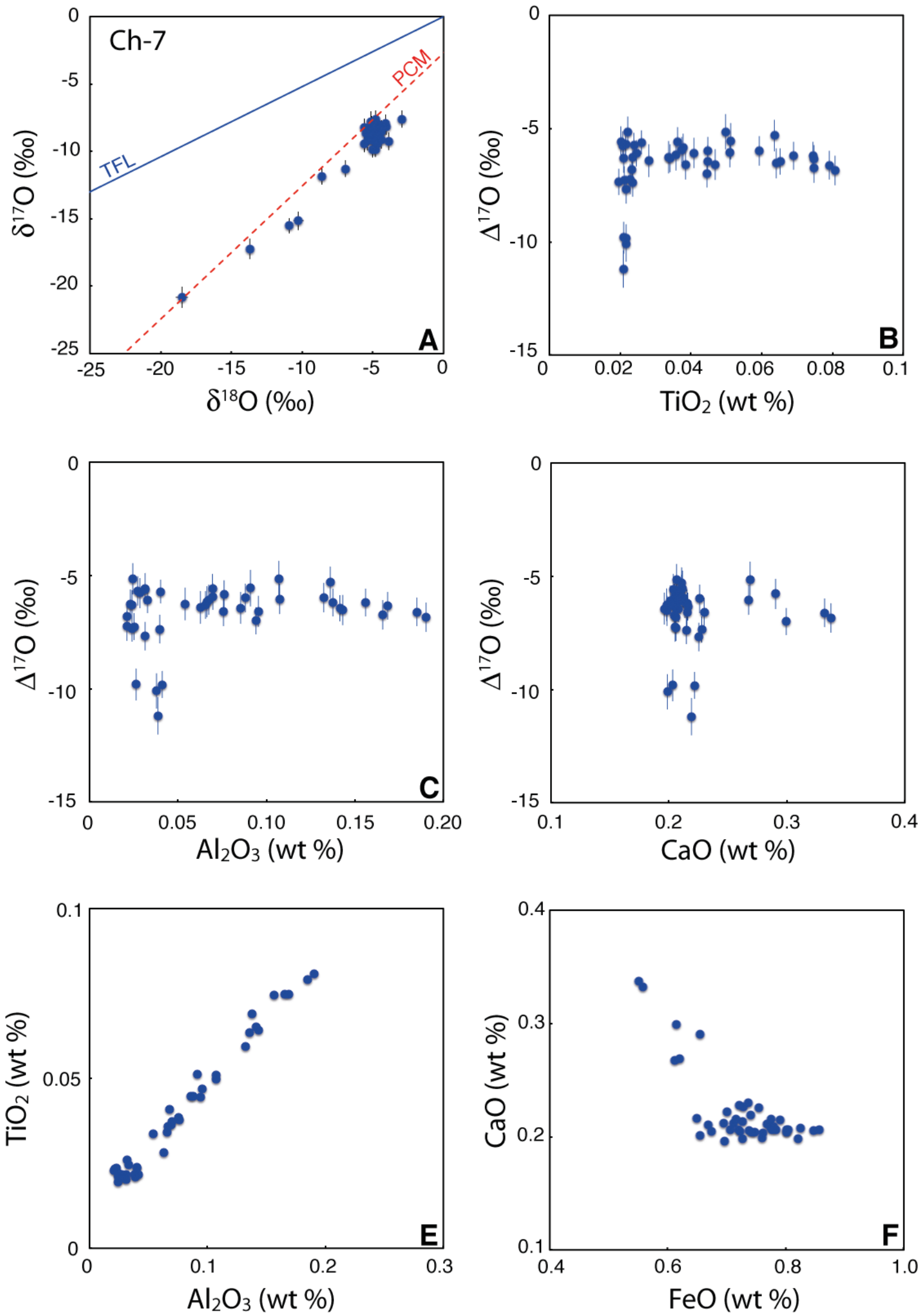

Fig. 4 


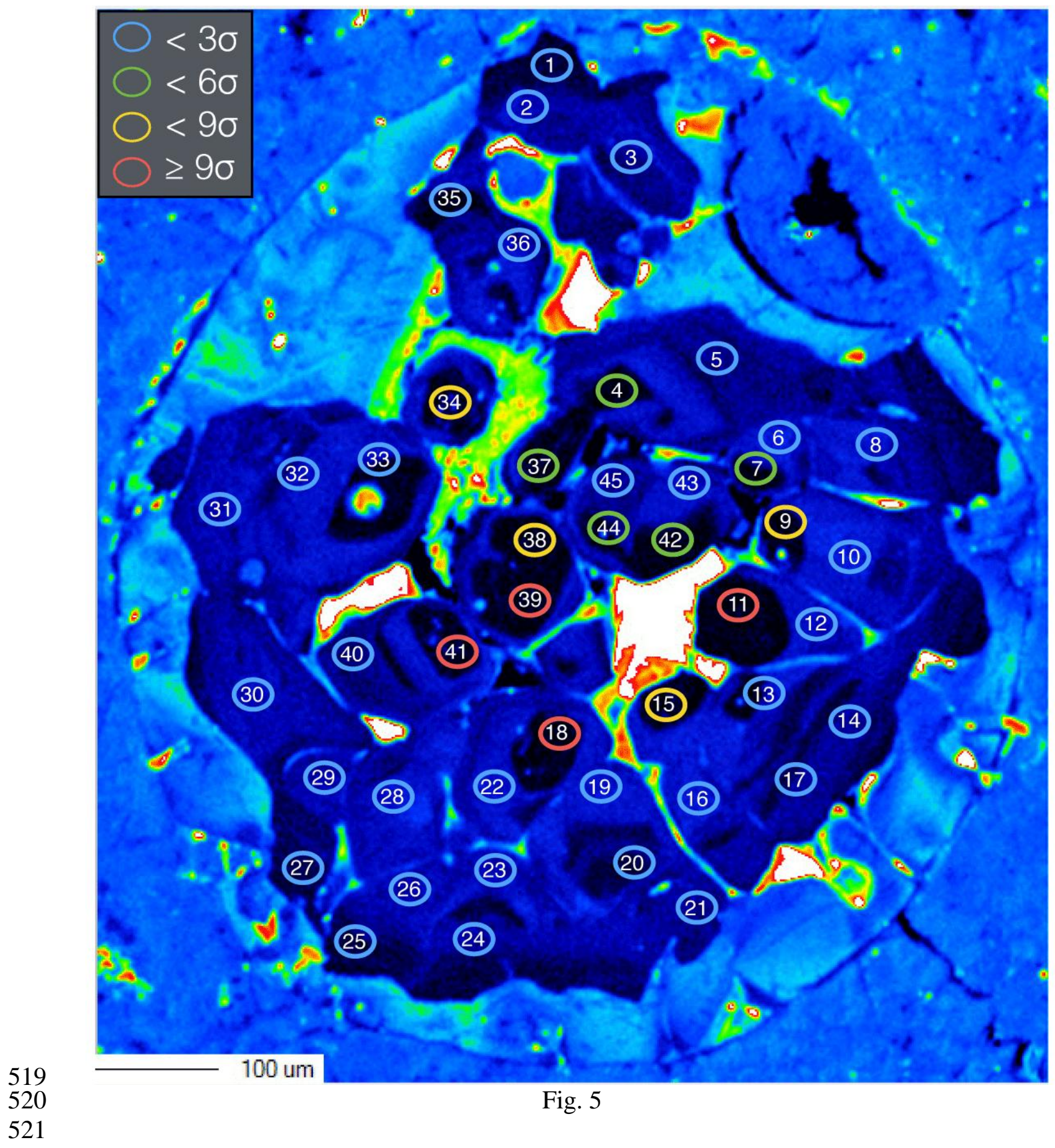




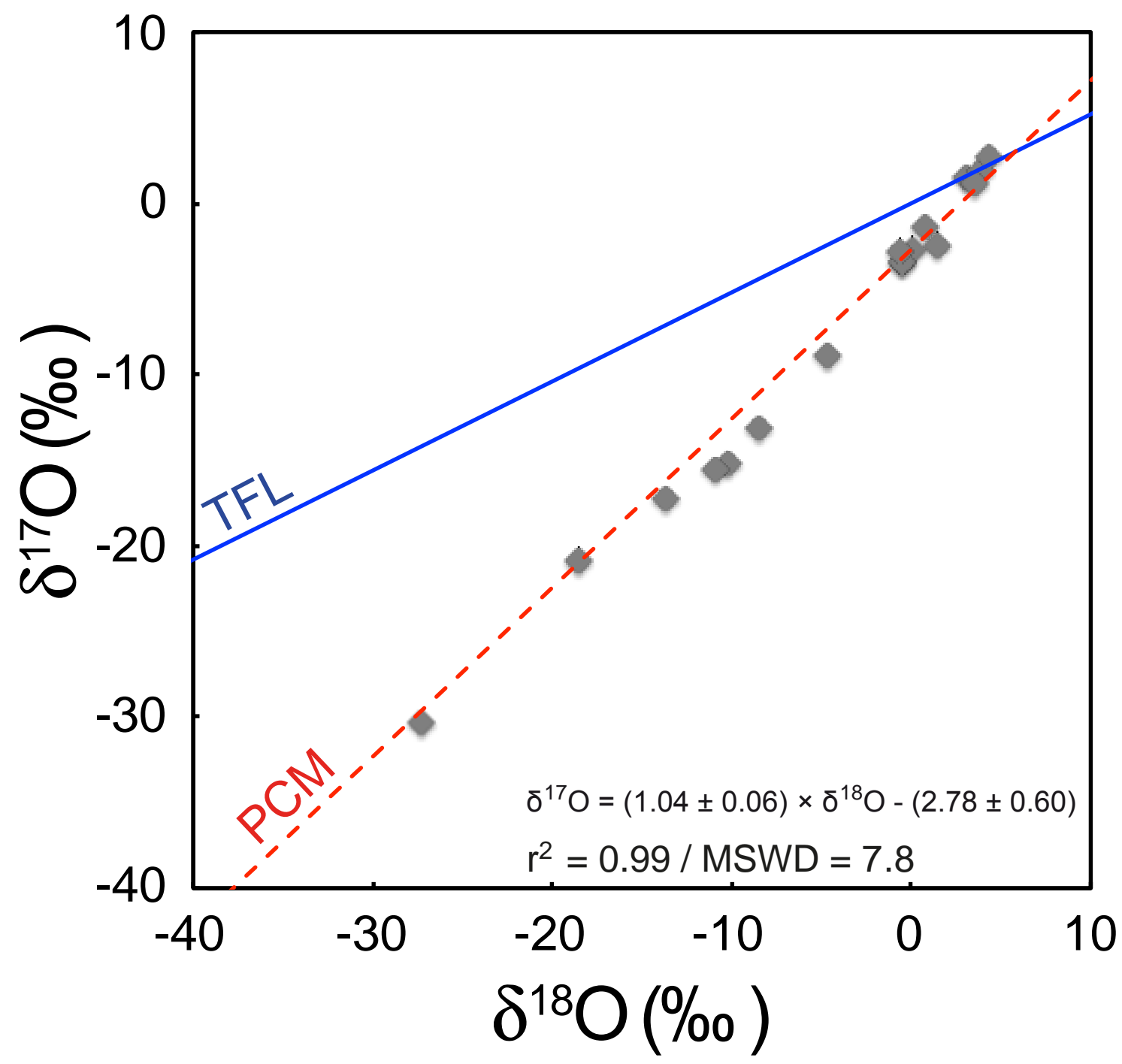

522
523

Fig. 6

524

525

526

527

528

529 


\begin{tabular}{|c|c|c|c|c|c|c|c|c|c|}
\hline chondrite & chondrule \# & olivine type & $\mathrm{n}$ & ${ }^{18} \mathrm{O}$ & $2 \sigma$ & ${ }^{17} 0$ & $2 \sigma$ & ${ }^{17} \mathrm{O}$ & $2 \sigma$ \\
\hline \multirow[t]{11}{*}{ NWA 5958} & Ch-1 (PO) & host & 35 & -4.99 & 0.25 & -8.61 & 0.71 & -6.02 & 0.72 \\
\hline & & relict & & -0.48 & 0.22 & -3.49 & 0.56 & -3.24 & 0.57 \\
\hline & & relict & & 0.05 & 0.25 & -2.67 & 0.75 & -2.69 & 0.76 \\
\hline & & relict & & 3.06 & 0.26 & 1.56 & 0.59 & -0.03 & 0.60 \\
\hline & & relict & & -0.46 & 0.28 & -3.42 & 0.63 & -3.18 & 0.65 \\
\hline & & relict & & 3.90 & 0.26 & 1.87 & 0.66 & -0.15 & 0.68 \\
\hline & & relict & & 0.74 & 0.22 & -1.39 & 0.68 & -1.77 & 0.69 \\
\hline & & relict & & 1.46 & 0.25 & -2.42 & 0.75 & -3.18 & 0.76 \\
\hline & & relict & & -0.63 & 0.28 & -2.86 & 0.88 & -2.54 & 0.89 \\
\hline & & relict & & 4.30 & 0.25 & 2.75 & 0.68 & 0.52 & 0.70 \\
\hline & & relict & & 3.49 & 0.25 & 1.15 & 0.72 & -0.67 & 0.73 \\
\hline \multirow[t]{5}{*}{ NWA 5958} & $\mathrm{Ch}-7$ (PO) & host & 41 & -4.90 & 0.23 & -8.82 & 0.63 & -6.27 & 0.64 \\
\hline & & relict & & -10.26 & 0.37 & -15.15 & 0.68 & -9.81 & 0.71 \\
\hline & & relict & & -10.91 & 0.26 & -15.51 & 0.57 & -9.83 & 0.59 \\
\hline & & relict & & -13.70 & 0.24 & -17.23 & 0.76 & -10.11 & 0.77 \\
\hline & & relict & & -18.49 & 0.42 & -20.82 & 0.79 & -11.20 & 0.82 \\
\hline \multirow[t]{4}{*}{ NWA 5958} & Ch-2 (POP) & host & 25 & 1.97 & 0.26 & -1.97 & 0.66 & -3.00 & 0.67 \\
\hline & & relict & & -27.35 & 0.23 & -30.34 & 0.63 & -16.12 & 0.64 \\
\hline & & relict & & -4.63 & 0.27 & -8.85 & 0.68 & -6.44 & 0.69 \\
\hline & & relict & & -8.50 & 0.23 & -13.16 & 0.65 & -8.75 & 0.66 \\
\hline
\end{tabular}

Table 1: Oxygen isotopic compositions of host and relict olivine grains in chondrules of chondrite NWA 5958. Relict grains correspond to those with low Ti contents and $\Delta^{17} \mathrm{O}$ values outside $3 \sigma$ of the average homogenous chondrule phase $\Delta^{17} \mathrm{O}$ value (Ushikubo et al., 2012). 


\section{References}

Aléon J. \& Bourrot-Denise M., 2008, Mineralogy and petrography of a spectacular refractory inclusion that underwent chondrule formation (abstract \#1638). 39th Lunar and Planetary Science Conference. CD-ROM.

Baecker, B., Rubin, A.E., Wasson, J.T., 2017. Secondary melting events in Semarkona chondrules revealed by compositional zoning in low-Ca pyroxene. Geochim. Cosmochim. Acta 211, 256-279. doi:10.1016/j.gca.2017.05.013

Batanova, V.G., Sobolev, A.V., Kuzmin, D.V., 2015. Trace element analysis of olivine: High precision analytical method for JEOL JXA-8230 electron probe microanalyser. Chemical Geology 419, 149-157. doi:10.1016/j.chemgeo.2015.10.042

Chaussidon, M., Libourel, G., Krot, A.N., 2008. Oxygen isotopic constraints on the origin of magnesian chondrules and on the gaseous reservoirs in the early Solar System. 72, 1924-1938. doi:10.1016/j.gca.2008.01.015

Clayton, R.N., 2003. Oxygen Isotopes in Meteorites, In Treatise on Geochemistry, Volume 1. Editor: Andrew M. Davis. Executive Editors: Heinrich D. Holland and Karl K. Turekian. 129-142. doi:10.1016/b0-08-043751-6/01063-x

Cohen, B.A., Hewins, R.H., Alexander, C.M.O., 2004. The formation of chondrules by open-system melting of nebular condensates. Geochim. Cosmochim. Acta 68, 1661-1675. doi:10.1016/j.gca.2003.09.009

Ebel, D.S., 2006. Condensation of rocky material in astrophysical environments. In Meteorites and the Early Solar System II, D. S. Lauretta and H. Y. McSween Jr. (eds.), University of Arizona Press, Tucson, 943 pp., p.253-277.

Ebel, D.S., Grossman, L., 2000. Condensation in dust-enriched systems. Geochim. Cosmochim. Acta 64, 339-366. doi:10.1016/s0016-7037(99)00284-7

Eiler, J.M., 2001. Oxygen Isotope Variations of Basaltic Lavas and Upper Mantle Rocks. Reviews in Mineralogy and Geochemistry 43, 319-364. doi:10.2138/gsrmg.43.1.319

Friend P., Hezel D.C., Mucershi D., 2016, The conditions of chondrule formation, Part II: Open System, Geochim. Cosmochim. Acta 173, 198-209.

Fokin, V.M., Zanotto, E.D., Yuritsyn, N.S., Schmelzer, J.W.P., 2006. Homogeneous crystal nucleation in silicate glasses: A 40 years perspective. Journal of Non-Crystalline Solids 352, 2681-2714. doi:10.1016/j.jnoncrysol.2006.02.074

Greenwood, R.C., Burbine, T.H., Miller, M.F., Franchi, I.A., 2016. Melting and differentiation of early-formed asteroids: The perspective from high precision oxygen isotope studies. Chemie der Erde - Geochemistry 1-43. doi:10.1016/j.chemer.2016.09.005

Hewins, R. H., Connolly, H. C., Logfren, G. E. J., and Libourel, G., 2005, Experimental Constraints on Chondrules Formation, Chondrites and the Protoplanetary Disk, ASP Conference Series, Vol. 341, San Fransisco: Astronomical Society of the Pacific, Hawai'i, p. 286.

Hezel D. C., Palme H., Brenker F. E., and Nasdala L. 2003. Evidence for fractional condensation and reprocessing at high temperatures in $\mathrm{CH}$ chondrites. Meteoritics \& Planetary Science 38:11991215.

Hezel, D. C., Palme, H., Nasdala, L., and Brenker, F. E., 2006. Origin of $\mathrm{SiO}_{2}$-rich components in ordinary chondrites. Geochemica and Cosmochemica Acta 70, 1548-1564.

Hezel D.C., Palme H., 2007. The conditions of chondrule formation, Part 1: Closed system. Geochim. Cosmochim. Acta 71, 4092-4107. doi: 10.1016/j.gca.2007.06.035

Jacquet, E., Alard, O., Gounelle, M., 2015. Trace element geochemistry of ordinary chondrite chondrules: The type I/type II chondrule dichotomy. Geochim. Cosmochim. Acta 155, 47-67. doi:10.1016/j.gca.2015.02.005

Jacquet, E., Alard, O., Gounelle, M., 2012. Chondrule trace element geochemistry at the mineral scale. Meteoritics \& Planetary Science 47, 1695-1714. doi:10.1111/maps.12005

Jacquet, E., Barrat, J.-A., Beck, P., Caste, F., Gattacceca, J., Sonzogni, C., Gounelle, M., 2016. Northwest Africa 5958: A weakly altered CM-related ungrouped chondrite, not a CI3. Meteorit Planet Sci 51, 851-869. doi:10.1111/maps.12628 
Jacquet, E., Marrocchi, Y., 2017. Chondrule heritage and thermal histories from trace element and oxygen isotope analyses of chondrules and amoeboid olivine aggregates. Meteorit Planet Sci 58, 3451-23. doi:10.1111/maps.12985

Jones, R.H., 2012. Petrographic constraints on the diversity of chondrule reservoirs in the protoplanetary disk. Meteoritics \& Planetary Science 47, 1176-1190. doi:10.1111/j.19455100.2011.01327.x

Jones, R.H., 1996. FeO-rich, porphyritic pyroxene chondrules in unequilibrated ordinary chondrites. Geochim. Cosmochim. Acta 60, 3115-3138. doi:10.1016/0016-7037(96)00152-4

Jones, R.H., Leshin, L.A., Guan, Y., Sharp, Z.D., 2004. Oxygen isotope heterogeneity in chondrules from the Mokoia CV3 carbonaceous chondrite. Geochim. Cosmochim. Acta 68, 3423-3438. doi:10.1016/j.gca.2004.01.013

Jones, R. H. and Scott, E. R. D., 1989, Petrology and thermal history of type IA chondrules in the Semarkona (LL3.0) chondrite, Lunar and Planetary Science Conference 19th, Lunar Planet. Inst., Houston, 523-536

Kimura, M., Grossman, J.N., Weisberg, M.K., 2011. Fe-Ni metal and sulfide minerals in CM chondrites: An indicator for thermal history. Meteoritics \& Planetary Science 46, 431-442. doi:10.1111/j.1945-5100.2010.01164.x

Kita, N.T., Nagahara, H., Tachibana, S., Tomomura, S., Spicuzza, M.J., Fournelle, J.H., Valley, J.W., 2010. High precision SIMS oxygen three isotope study of chondrules in LL3 chondrites: Role of ambient gas during chondrule formation. Geochim. Cosmochim. Acta 74, 6610-6635. doi:10.1016/j.gca.2010.08.011

Krot A. N. and Keil K. 2002. Anorthite-rich chondrules in CR and CH carbonaceous chondrites: Genetic link between $\mathrm{Ca}$, Al-rich inclusions and ferromagnesian chondrules.Meteoritics \& Planetary Science 37:91-111.

Krot, A.N., Petaev, M.I., Russel, S.S., Itoh, S., Fagan, T.J., Yurimoto, H., Chizmadia, L., Weisberg, M.K., Komatsu, M., Ulyanov, A.A., Keil, K., 2004. Amoeboid olivine aggregates and related objects in carbonaceous chondrites: records of nebular and asteroid processes. Chemie der Erde Geochemistry 64, 185-239. doi:10.1016/j.chemer.2004.05.001

Krot A. N., Amelin Y., Bland P., Ciesla F. J., Connelly J., Davis A. M., Huss G. R., Hutcheon I. D., Makide K., Nagashima K., Nyquist L. E., Russell S. S., Scott E. R. D., Thrane K., Yurimoto H., and Yin Q.-Z. 2009. Origin and chronology of chondritic components: A review. Geochimica et Cosmochimica Acta 73:4963-4997.

Kunihiro, Tak, Rubin, A.E., Wasson, J.T., 2005. Oxygen-isotopic compositions of low-FeO relicts in high-FeO host chondrules in Acfer 094, a type 3.0 carbonaceous chondrite closely related to CM. Geochim. Cosmochim. Acta 69, 3831-3840. doi:10.1016/j.gca.2005.01.031

Kunihiro, Takuya, Rubin, A.E., McKeegan, K.D., Wasson, J.T., 2004. Oxygen-isotopic compositions of relict and host grains in chondrules in the Yamato 81020 CO3.0 chondrite. Geochim. Cosmochim. Acta 68, 3599-3606. doi:10.1016/j.gca.2004.02.011

Lemelle, L., Guyot, F., Leroux, H., Libourel, G., 2001. An experimental study of the external reduction of olivine single crystals. American Mineralogist 86, 47-54. doi:10.2138/am-2001-0106

Leroux, H., Libourel, G., Lemelle, L., Guyot, F., 2003. Experimental study and TEM characterization of dusty olivines in chondrites: Evidence for formation by in situ reduction. Meteoritics \& Planetary Science 38, 81-94. doi:10.1111/j.1945-5100.2003.tb01047.x

Libourel, G., 1999. Systematics of calcium partitioning between olivine and silicate melt: implications for melt structure and calcium content of magmatic olivines. Contrib Mineral Petrol 136, 63-80. doi:10.1007/s004100050524

Libourel, G., Chaussidon, M., 2011. Oxygen isotopic constraints on the origin of Mg-rich olivines from chondritic meteorites. Earth Planet. Sci. Lett. 301, 9-21. doi:10.1016/j.eps1.2010.11.009

Libourel, G., Krot, A., Tissandier, L., 2006. Role of gas-melt interaction during chondrule formation. Earth and Planetary Science Letters 251, 232-240. doi:10.1016/j.eps1.2006.09.011

Libourel, G., Krot, A.N., 2007. Evidence for the presence of planetesimal material among the precursors of magnesian chondrules of nebular origin. Earth and Planetary Science Letters 254, 18. doi:10.1016/j.epsl.2006.11.013 
McCanta M.C., Beckett J.R. \& Stolper E.M. (2016) Correlations and zoning patterns of phosphorous and chromium in olivine from $\mathrm{H}$ chondrites and the LL chondrite Sermakona. Meteoritics \& Planetary Science 51, 520-546.

Marrocchi Y., Chaussidon M., Piani L. and Libourel G. (2016) Early scattering of the solar protoplanetary disk recorded in meteoritic chondrules. Sci. Adv. 2, e1601001.

Marrocchi, Y., Bekaert, D.V., Piani, L., 2018. Origin and abundance of water in carbonaceous asteroids. Earth and Planetary Science Letters 482, 23-32. doi:10.1016/j.eps1.2017.10.060

Marrocchi, Y., Chaussidon, M., 2015. A systematic for oxygen isotopic variation in meteoritic chondrules. Earth Planet. Sci. Lett. 430, 308-315. doi:10.1016/j.eps1.2015.08.032

Marrocchi, Y., Libourel, G., 2013. Sulfur and sulfides in chondrules. Geochim. Cosmochim. Acta 119, 117-136. doi:10.1016/j.gca.2013.05.020

Misawa K. and Nakamura N. 1988. Demonstration of REE fractionation among individual chondrules from the Allende (CV3) chondrite. Geochimica et Cosmochimica Acta 52:1699-1710.

Nagahara, H., 1981. Evidence for secondary origin of chondrules. Nature 292, 135-136. doi:10.1038/292135a0

Pack, A., Palme, H., 2003. Partitioning of $\mathrm{Ca}$ and $\mathrm{Al}$ between forsterite and silicate melt in dynamic systems with implications for the origin of $\mathrm{Ca}$, Al-rich forsterites in primitive meteorites. Meteoritics \& Planetary Science 38, 1263-1281. doi:10.1111/j.1945-5100.2003.tb00312.x

Pack, A., Palme, H., Shelley, J.M.G., 2005. Origin of chondritic forsterite grains. Geochim. Cosmochim. Acta 69, 3159-3182. doi:10.1016/j.gca.2005.01.013

Pack, A., Yurimoto, H., Palme, H., 2004. Petrographic and oxygen-isotopic study of refractory forsterites from R-chondrite Dar al Gani 013 (R3.5-6), unequilibrated ordinary and carbonaceous chondrites. Geochim. Cosmochim. Acta 68, 1135-1157. doi:10.1016/j.gca.2003.07.014

Petaev, M.I., Wood J.A., 2005. Meteoritic Constraints on Temperatures, Pressures, Cooling Rates, Chemical Compositions and Modes of Condensation in the Solar Nebula, In Chondrites and the Protoplanetary Disk, ASP Conference Series, Vol. 341, Proceedings of a workshop held 8-11 November 2004 in Kaua'i, Hawai'i. Edited by Alexander N. Krot, Edward R. D. Scott, and Bo Reipurth. San Francisco: Astronomical Society of the Pacific, p.373

Piani, L., Marrocchi, Y., Libourel, G., Tissandier, L., 2016. Magmatic sulfides in the porphyritic chondrules of EH enstatite chondrites. Geochim. Cosmochim. Acta 195, 84-99. doi:10.1016/j.gca.2016.09.010

Rambaldi, E.R., 1981. Relict grains in chondrules. Nature 293, 558-561. doi:10.1038/293558a0

Richet, P., Bottinga, Y., Javoy, M., 1977. A Review of Hydrogen, Carbon, Nitrogen, Oxygen, Sulphur, and Chlorine Stable Isotope Fractionation Among Gaseous Molecules. Annu. Rev. Earth Planet. Sci. 5, 65-110. doi:10.1146/annurev.ea.05.050177.000433

Rudraswami, N.G., Ushikubo, T., Nakashima, D., Kita, N.T., 2011. Oxygen isotope systematics of chondrules in the Allende CV3 chondrite: High precision ion microprobe studies. Geochim. Cosmochim. Acta 75, 7596-7611. doi:10.1016/j.gca.2011.09.035

Russell S. S., MacPherson G. J., Leshin L. A., and McKeegan K. D. 2000. ${ }^{16}$ O enrichments in aluminum-rich chondrules from ordinary chondrites. Earth and Planetary Science Letters 184:5774.

Russell, S.S., Krot, A.N., Huss, G.R, Keil K., Itoh S., Yurimoto H., MacPherson G.J., 2005, The genetic relationship between refractory inclusions and chondrules. In Chondrites and the Protoplanetary Disk, ASP Conference Series, Vol. 341, Proceedings of a workshop held 8-11 November 2004 in Kaua'i, Hawai'i. Edited by Alexander N. Krot, Edward R. D. Scott, and Bo Reipurth. San Francisco: Astronomical Society of the Pacific, 2005, p.317.

Ruzicka, A., Floss, C., Hutson, M., 2012. Amoeboid olivine aggregates (AOAs) in the Efremovka, Leoville and Vigarano (CV3) chondrites: A record of condensate evolution in the solar nebula. Geochim. Cosmochim. Acta 79, 79-105. doi:10.1016/j.gca.2011.11.043

Ruzicka, A., Hiyagon, H., Hutson, M., Floss, C., 2007. Relict olivine, chondrule recycling, and the evolution of nebular oxygen reservoirs. Earth and Planetary Science Letters 257, 274-289. doi:10.1016/j.eps1.2007.02.037

Ryerson, F.J., Durham, W.B., Cherniak, D.J., Lanford, W.A., 1989. Oxygen diffusion in olivine: Effect of oxygen fugacity and implications for creep. Journal of Geophysical Research 94, 41054118. doi:10.1029/JB094iB04p04105 
Sakyi P.A., Tanaka R., Kobayashi K., Nakamura E., 2012. Inherited Pb isotopic records in olivine antercryst-hosted melt inclusions from Hawaiian lavas. Geochim. Cosmochim. Acta 95, 169-195.

Schrader, D.L., Connolly, H.C., Jr, Lauretta, D.S., Nagashima, K., Huss, G.R., Davidson, J., Domanik, K.J., 2013. The formation and alteration of the Renazzo-like carbonaceous chondrites II: Linking O-isotope composition and oxidation state of chondrule olivine. Geochim. Cosmochim. Acta 101, 302-327. doi:10.1016/j.gca.2012.09.045

Schrader, D.L., Connolly, H.C., Jr, Lauretta, D.S., Zega, T.J., Davidson, J., Domanik, K.J., 2015. The formation and alteration of the Renazzo-like carbonaceous chondrites III: Toward understanding the genesis of ferromagnesian chondrules. Meteorit Planet Sci 50, 15-50. doi:10.1111/maps.12402

Schrader, D.L., Nagashima, K., Waitukaitis, S.R., Davidson, J., McCoy, T.J., Connolly, H.C., Lauretta, D.S., 2018. The retention of dust in protoplanetary disks: Evidence from agglomeratic olivine chondrules from the outer Solar System. Geochim. Cosmochim. Acta 223, 405-421. doi:10.1016/j.gca.2017.12.014

Scott, E., Jones, R.H., 1990. Disentangling nebular and asteroidal features of C03 carbonaceous chondrite meteorites. exported from refbase Geochim. Cosmochim. Acta 54, 2485-2502. doi:10.1016/0016-7037(90)90235-d

Sobolev, A.V., Asafov, E.V., Gurenko, A.A., Arndt, N.T., Batanova, V.G., Portnyagin, M.V., GarbeSchönberg, D., Krasheninnikov, S.P., 2016. Komatiites reveal a hydrous Archaean deep-mantle reservoir. Nature 531, 628-632. doi:10.1038/nature 17152

Soulié, C., Libourel, G., Tissandier, L., 2016. Olivine dissolution in molten silicates: An experimental study with application to chondrule formation. Meteoritics \& Planetary Science 52, 225-250. doi:10.1111/maps.12792

Sugiura, N., Petaev, M.I., Kimura, M., Miyazaki A., Hiyagon, H., 2009. Nebular history of amoeboid olivine aggregates. Meteoritics \& Planetary Science 44, 559-572. doi:10.1111/j.19455100.2009.tb00751.x

Tenner, T.J., Nakashima, D., Ushikubo, T., Kita, N.T., Weisberg, M.K., 2015. Oxygen isotope ratios of $\mathrm{FeO}$-poor chondrules in $\mathrm{CR} 3$ chondrites: Influence of dust enrichment and $\mathrm{H} 2 \mathrm{O}$ during chondrule formation. Geochim. Cosmochim. Acta 148, 228-250. doi:10.1016/j.gca.2014.09.025

Tenner, T.J., Ushikubo, T., Kurahashi, E., Kita, N.T., Nagahara, H., 2013. Oxygen isotope systematics of chondrule phenocrysts from the CO3.0 chondrite Yamato 81020: Evidence for two distinct oxygen isotope reservoirs. Geochim. Cosmochim. Acta 102, 226-245. doi:10.1016/j.gca.2012.10.034.

Tenner T.J., Ushikubo T., Nakashima D., Schrader D.L., Weisberg M.K., Kimura M., Kita N.T. (In press) Oxygen Isotope Characteristics of Chondrules from Recent Studies by Secondary Ion Mass Spectrometry. In Chondrules and the protoplanetary disk. Cambridge University Press.

Tissandier, L., Libourel, G., Robert, F., 2002. Gas-melt interactions and their bearing on chondrule formation. Meteoritics \& Planetary Science 37, 1377-1389. doi:10.1111/j.19455100.2002.tb01035.x

Ushikubo, T., Kimura, M., Kita, N.T., Valley, J.W., 2012. Primordial oxygen isotope reservoirs of the solar nebula recorded in chondrules in Acfer 094 carbonaceous chondrite. Geochim. Cosmochim. Acta 90, 242-264. doi:10.1016/j.gca.2012.05.010

Verdier-Paoletti, M.J., Marrocchi, Y., Avice, G., Roskosz, M., Gurenko, A., Gounelle, M., 2017. Oxygen isotope constraints on the alteration temperatures of CM chondrites. Earth Planet. Sci. Lett. 458, 273-281. doi:10.1016/j.epsl.2016.10.055

Weisberg, M.K., Connolly, H.C., Ebel, D.S., 2004. Petrology and origin of amoeboid olivine aggregates in CR chondrites. Meteoritics \& Planetary Science 39, 1741-1753. doi:10.1111/j.19455100.2004.tb00070.x

Whattam, S.A., Hewins, R.H., 2009. Granoblastic olivine aggregates as precursors of Type I chondrules: An experimental test. Geochim. Cosmochim. Acta 73, 5460-5482. doi:10.1016/j.gca.2009.04.014

Whattam, S.A., Hewins, R.H., Cohen, B.A., Seaton, N.C., Prior, D.J., 2008. Granoblastic olivine aggregates in magnesian chondrules: Planetesimal fragments or thermally annealed solar nebula condensates? Earth and Planetary Science Letters 269, 200-211. doi:10.1016/j.eps1.2008.02.013 
Yurimoto, H., Wasson, J.T., 2002. Extremely rapid cooling of a carbonaceous-chondrite chondrule containing very ${ }^{16} \mathrm{O}$-rich olivine and a ${ }^{26} \mathrm{Mg}$-excess. Geochim. Cosmochim. Acta 66, 4355-4363. doi:10.1016/s0016-7037(02)01218-8 